\title{
Femtosecond Pump-Probe Studies of Nitrosyl Chloride Photochemistry in Solution
}

\author{
Catherine C. Cooksey, Kevin J. Johnson, and Philip J. Reid* \\ Box 351700, Department of Chemistry, University of Washington, Seattle, Washington 98195 \\ Received: April 3, 2006; In Final Form: May 9, 2006
}

\begin{abstract}
We present a femtosecond pump-probe study of the primary events of nitrosyl chloride (CINO) photochemistry in solution. Following $266 \mathrm{~nm}$ photolysis, the resulting evolution in optical density is measured for ClNO dissolved in acetonitrile, chloroform, and dichloromethane. The results demonstrate that photolysis results in the production of a photoproduct that has an absorption band maximum at $295 \mathrm{~nm}$ in acetonitrile and $330 \mathrm{~nm}$ in chloroform and dichloromethane. To determine the extent of $\mathrm{Cl}$ production, comparative photochemical studies of methyl hypochlorite $(\mathrm{MeOCl})$ and $\mathrm{ClNO}$ are performed. Photolysis of $\mathrm{MeOCl}$ in solution results in the production of the $\mathrm{Cl}$ :solvent charge-transfer complex; therefore, a comparison of the spectral evolution observed following $\mathrm{MeOCl}$ and $\mathrm{ClNO}$ photolysis under identical photolysis conditions is performed to determine the extent of $\mathrm{Cl}$ production following $\mathrm{CINO}$ photolysis. We find that similar to the gas-phase photochemistry, $\mathrm{Cl}$ and $\mathrm{NO}$ formation is the dominant photochemical channel in acetonitrile. However, the photochemistry in chloroform and dichloromethane is more complex, with a second product formed in addition to $\mathrm{Cl}$ and NO. It is proposed that in these solvents photoisomerization also occurs, resulting in the production of $\mathrm{ClON}$. The results presented here represent the first detailed examination of the solution phase photochemistry of CINO.
\end{abstract}

\section{Introduction}

A significant challenge in atmospheric chemistry is to understand the fundamental aspects of phase-dependent photochemical reactivity. For example, the environment-dependent reactivity of halooxides, such as chlorine dioxide $(\mathrm{OClO})$, has attracted a significant amount of attention due to the contribution of these compounds to the stratospheric chlorine budget. ${ }^{1-4}$ Photoexcitation of gaseous $\mathrm{OClO}$ results predominately in the formation of $\mathrm{ClO}$ and $\mathrm{O}$, with a small amount of $\mathrm{Cl}$ and $\mathrm{O}_{2}$ also produced ${ }^{5-7}$ However, the photochemical production of the $\mathrm{ClOO}$ isomer is observed in low-temperature matrixes, ${ }^{8-10}$ and photolysis of solution-phase $\mathrm{OClO}$ results in both $\mathrm{ClO} / \mathrm{O}$ and $\mathrm{ClOO}$ production. ${ }^{11-21}$ Another halooxide, dichlorine monoxide $(\mathrm{ClOCl})$, demonstrates phase-dependent photochemical reactivity similar to $\mathrm{OClO}$. In the gas phase, direct dissociation to form $\mathrm{Cl}$ and $\mathrm{ClO}$ is the dominant photochemical pathway, ${ }^{22-30}$ whereas, photoexcitation in low-temperature matrixes and in solution results in the formation of the isomer, ClClO. ${ }^{9,31-35}$

Given the substantial information regarding the phasedependent photochemical reactivity of halooxides, it is reasonable to ask if similar environment-dependent reactivity is observed for related compounds. To address this question, we have investigated the condensed-phase photochemistry of nitrosyl chloride (CINO). CINO participates in both stratospheric and tropospheric chemistry. ${ }^{36,37}$ Surface reactions of HONO on frozen $\mathrm{HCl}$ result in the formation of $\mathrm{ClNO}$ in the upper troposphere and stratosphere, whereas the reaction of sea salt with $\mathrm{NO}_{2}$ provides for CINO production in the lower troposphere. ${ }^{38}$ The photochemistry of gaseous CINO is dominated by formation of the photoproducts, $\mathrm{NO}\left({ }^{2} \Pi \pm 1 / 2, \pm 3 / 2\right)$ and $\mathrm{Cl}$ $\left({ }^{2} \mathrm{P}_{1 / 2,3 / 2}\right)$, with near-unity quantum yield. ${ }^{25,36,39-56}$ The absorption spectrum of CINO consists of a series of bands referred to as

* To whom correspondence should be addressed. E-mail: preid@ chem.washington.edu. the $\mathrm{K}$ through $\mathrm{A}$ bands as one proceeds from low to high energy. ${ }^{57,58}$ The A-band dominates the absorption spectrum and has an absorption maximum of $196 \mathrm{~nm}$ in the gas phase. Following A-band photoexcitation vibrationally excited NO is produced. ${ }^{23,40,41,50,51,53}$ A bimodal distribution of $\mathrm{NO}$ vibrational energy was observed, suggesting that dissociation is mediated by two or more electronic excited states. ${ }^{50,53}$ The production of the $\mathrm{Cl}\left({ }^{2} \mathrm{P}_{3 / 2}\right)$ and $\mathrm{Cl}^{*}\left({ }^{2} \mathrm{P}_{1 / 2}\right)$ following $\mathrm{ClNO}$ photolysis has also been interpreted in terms of multiple excited states residing within the A-band. ${ }^{52,54,55}$ This hypothesis is supported by theoretical studies of CINO. ${ }^{45,59-61}$ However, UV resonance Raman intensity analysis studies of gaseous CINO could be explained in terms of a single excited state. ${ }^{56}$

There are only a handful of studies regarding the photochemistry of CINO in condensed environments. A study of CINO surface films found that $193 \mathrm{~nm}$ photodissociation results predominantly in dissociation to form $\mathrm{Cl}$ and $\mathrm{NO}$, similar to the behavior observed in the gas phase. ${ }^{62}$ However, matrix isolation studies of $\mathrm{ClNO}$ observed the formation of the structural isomer, ClON. ${ }^{63,64}$ Only recently has the solutionphase photochemistry of ClNO been investigated. Resonance Raman studies of CINO dissolved in cyclohexane and acetonitrile have observed scattered intensity consistent with excitedstate structural evolution along all three normal coordinates. ${ }^{65,66}$ These studies also found that the resonance Raman depolarization ratios measured at excitation wavelengths spanning the A-band are less than $1 / 3$, consistent with the presence of at least two excited states.

In this paper, we describe femtosecond pump-probe studies of solution-phase CINO. Following $266 \mathrm{~nm}$ photoexcitation, the optical-density evolution from 256 to $375 \mathrm{~nm}$ is measured. The absorption spectra of CINO and its potential photoproducts are presented in Figure 1. To determine the dependence of the photochemistry on environment, experiments were performed on CINO dissolved in acetonitrile, chloroform, and dichloromethane. In all solvents, the photoinduced depletion of 


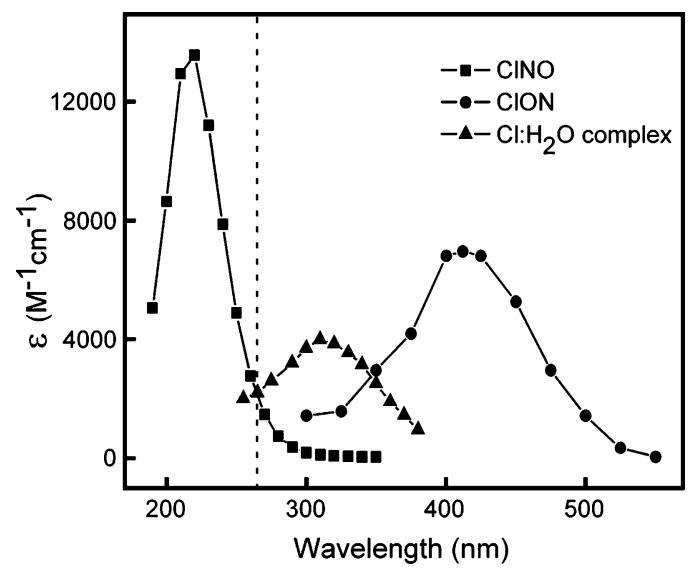

Figure 1. Absorption spectrum of $\mathrm{ClNO}$ and potential photoproducts. The molar absorptivity values for CINO correspond to this species dissolved in acetonitrile. ${ }^{66}$ The absorption spectrum of the structural isomer, $\mathrm{ClON}$, is for this species isolated in a low-temperature argon matrix ${ }^{64}$ and the absorption spectrum of the $\mathrm{Cl}: \mathrm{H}_{2} \mathrm{O}$ charge-transfer complex is taken from the literature. ${ }^{75}$ The dashed line indicates the excitation wavelength used in this study.

ground-state CINO is followed by the formation of photoproduct with an absorption band centered at $295 \mathrm{~nm}$ in acetonitrile, and $330 \mathrm{~nm}$ in chloroform and dichloromethane. The band reaches a maximum in optical density $\sim 4$ ps after photolysis and decays on the $\sim 1$ ns time scale. To differentiate between possible assignments for the photoproduct, a photochemical study of methyl hypochlorite $(\mathrm{MeOCl})$ dissolved in dichloromethane was performed. Recent work by Crim and co-workers has demonstrated that photoexcitation of $\mathrm{MeOCl}$ results in the production of $\mathrm{Cl}$; therefore, these studies allow for characterization of the optical-density evolution accompanying production of the $\mathrm{Cl}$ : solvent charge-transfer complex. ${ }^{67} \mathrm{~A}$ comparison of the transient absorption spectra for $\mathrm{MeOCl}$ and $\mathrm{CINO}$ measured under identical photolysis conditions, and calculations of the predicted optical-density change accompanying $\mathrm{Cl}$ production are performed to determine the quantum yield for formation of the $\mathrm{Cl}$ :solvent charge-transfer complex. We find that CINO photolysis in acetonitrile results predominantly in dissociation to form $\mathrm{Cl}$ and $\mathrm{NO}$, with a portion of these fragments undergoing geminate recombination to re-form the parent molecule. The photochemistry in chloroform and dichloromethane is more complex. Specifically, in addition to $\mathrm{Cl}$ and $\mathrm{NO}$ production another photoproduct channel is observed. It is proposed that in these solvents, photoisomerization also occurs, resulting in the production of the structural isomer, $\mathrm{ClON}$. The results presented here represent the first detailed study of CINO photochemistry in solution.

\section{Experimental Methods}

Figure 2 presents a schematic of the femtosecond pumpprobe spectrometer employed in these studies. An amplified Ti: sapphire laser (Spectra Physics Hurricane) produced $120 \mathrm{fs}$ pulses (full width at half-maximum) centered at $800 \mathrm{~nm}$ with an energy of $750 \mu \mathrm{J}$ and a repetition rate of $1 \mathrm{kHz}$. The amplifier output was separated into two beams, with $40 \%$ of the output used to generate the 266-nm pump field through third-harmonic generation (Spectra Physics TP-IA). The various probe wavelengths were generated with the remainder of the amplifier output as follows. For the $266 \mathrm{~nm}$ probe, the amplifier output was frequency tripled. Probe wavelengths of 256 and $284 \mathrm{~nm}$ were generated from the second harmonic of the sum-frequency field derived from the residual pump and signal or idler fields

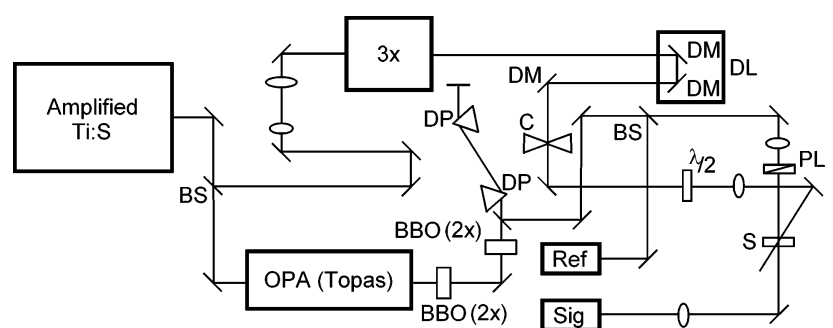

Figure 2. Schematic of the pump-probe spectrometer used in this study. The following abbreviations have been used: BS, beam splitter; OPA, optical parametric amplifier; $\mathrm{BBO}$, frequency doubling $\beta$-barium borate crystal; DP, Brewster dispersion prism; PL, calcite polarizer; S, sample; 3x, frequency tripler; DM, dichroic mirror; DL, optical delay line; $\mathrm{C}$, chopper; $\lambda / 2$, zero-order half-wave plate.

of an optical parametric amplifier (OPA, Quantronix TOPAS). The fourth harmonic of the signal field derived from the OPA was used to generate all other probe wavelengths (292, 304, $311,322,331,354$, and $375 \mathrm{~nm})$. All frequency conversions were performed using appropriate $\beta$-BBO crystals. Two $\mathrm{CaF}_{2}$ prisms were used to spectrally isolate the probe, and to compensate for group-velocity dispersion. A beam-splitter separated the probe into sample and reference beams with the probe polarization defined using a calcite polarizer. An opticaldelay line allowed for temporal delay between the pump and probe pulses. Rotational contributions to the measured opticaldensity evolution were minimized by orienting the pump polarization to $54.7^{\circ}$ relative to the probe with a zero-order halfwave plate. The instrument response as measured by the optical Kerr effect in water was $350 \pm 50$ fs at all probe wavelengths. The sample was delivered to a fused-silica flow cell equipped with $\mathrm{CaF}_{2}$ windows having a path of 0.095 or $0.2 \mathrm{~cm}$, and the flow rate was sufficient to replace the sample volume between photolysis events.

The pump-induced change in sample optical density was measured as follows. UV-enhanced photodiodes (Advanced Photonix, Inc. SD 200-13-23-242) detected the sample and reference beams. The photodiode outputs were processed using separate gated integrators (Stanford Research Systems SR250), and the integrator outputs were subtracted on a shot to shot basis. A mechanical chopper frequency modulated the pump beam at half the amplifier repetition rate. The difference in gated-integrator outputs was delivered to a computer where the voltage difference between adjacent laser shots was measured to determine the pump-induced change in optical density. An individual scan consisted of 1000-2000 laser shots per time point, with two or three scans averaged to produce the data shown here. All solvents demonstrated a minor contribution to the optical-density evolution at zero delay. This solvent-only contribution was removed by subtracting the measured solventonly response from that obtained with CINO present. Subtraction of the solvent contribution to the CINO spectra was considered complete when the solvent contributions occurring at zero time were removed. Kinetic parameters describing the optical-density evolution were determined by fitting the experimental evolution to a sum of exponentials convolved with the instrument response using the Levenberg-Marquardt algorithm. Visual inspection of the residuals and $\chi^{2}$ values were used to judge the goodness of the fit. The reported errors correspond to one standard deviation from the mean of multiple measurements taken $(\geq 3$ measurements).

Pump and probe pulse energies of 10.0 and $0.3 \mu \mathrm{J}$, respectively, were employed with all optical-density changes determined to scale linearly with a 4-fold increase in pump power. CINO samples were prepared as described in the literature. ${ }^{65,68}$ 


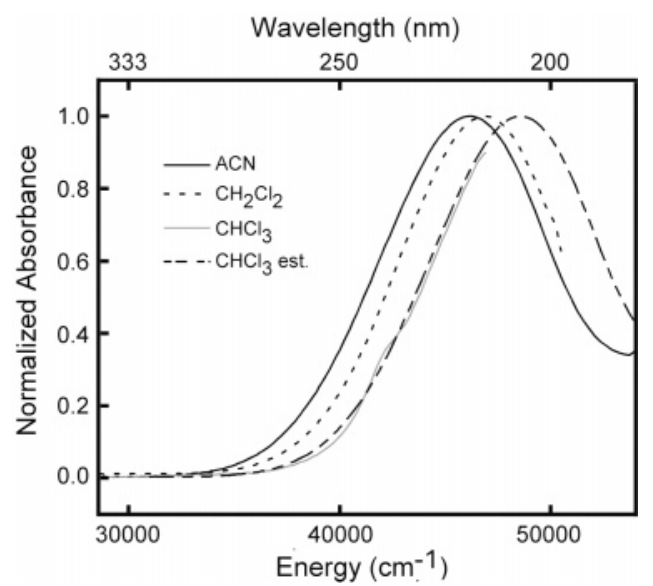

Figure 3. Normalized absorption spectra of $\mathrm{ClNO}$ dissolved in acetonitrile $(\mathrm{ACN}),{ }^{66}$ dichloromethane $\left(\mathrm{CH}_{2} \mathrm{Cl}_{2}\right)$, and chloroform $\left(\mathrm{CHCl}_{3}\right)$. The estimated absorption band for $\mathrm{ClNO}$ in chloroform $\left(\mathrm{CHCl}_{3}\right.$ est.) is also shown.

$\mathrm{UV}$ - vis absorption was used to determine the purity and optical density of the CINO solutions. For this study, sample optical densities of 0.7 , as measured using a $0.2 \mathrm{~cm}$ path length, were employed. To prevent degassing of CINO from solution, the stock solution was kept in the refrigerator and the sample solution was chilled in an ice bath during the experiment. Decomposition of the stock solution was not evident as determined by vis-UV spectra obtained before and after each experiment; however, fresh stock solutions were routinely employed to ensure sample integrity. For experiments in which the absolute change in optical density was determined, fresh samples of CINO were used for each individual measurement at a given probe wavelength. To reduce error associated with subtraction of the solvent contribution from the optical-density evolution, absolute optical-density changes were measured at the lowest pump energies possible $(1.6-7.2 \mu \mathrm{J})$. This resulted in essentially no solvent contribution for all probe wavelengths except 256 and $266 \mathrm{~nm}$. At these wavelengths, solvent absorption is the greatest at the shortest delay times (1 ps) and decreases with increased delay. The maximum optical-density change due to the solvent is $29 \pm 10 \%$ and $84 \pm 9 \%$ of the maximum change in optical density change of CINO (with solvent subtracted) at 1.2 ps for probe wavelengths of 256 and $266 \mathrm{~nm}$, respectively. It should be noted that photoproduct absorption is minimal in this wavelength region.

The optical-density evolution corresponding to the $\mathrm{Cl}$ :solvent charge-transfer complex was determined by the photodissociation of methyl hypochlorite $(\mathrm{MeOCl})$ in dichloromethane at 266 $\mathrm{nm}$ with pulse energies of $0.54 \mu \mathrm{J}$. The transient absorption spectrum of the Cl:solvent charge-transfer complex was measured using probe wavelengths from 292 to $375 \mathrm{~nm}$. The preparation of $\mathrm{MeOCl}$ in dichloromethane was performed according to the literature. ${ }^{67,69}$ Stock solutions were routinely made to ensure sample integrity. Fresh samples, having a $\mathrm{MeOCl}$ concentration of $1.1 \mathrm{M}$, were derived daily using the stock solution.

\section{Results}

Absorption Spectra. The absorption spectra of CINO dissolved in acetonitrile, dichloromethane, and chloroform are presented in Figure 3.The large absorption evident in the figure is referred to as the A-band. The maximum of the CINO A-band in acetonitrile is $217 \mathrm{~nm}\left(46083 \mathrm{~cm}^{-1}\right) .{ }^{66}$ Determination of the absorption maximum of $\mathrm{ClNO}$ dissolved in chloroform and

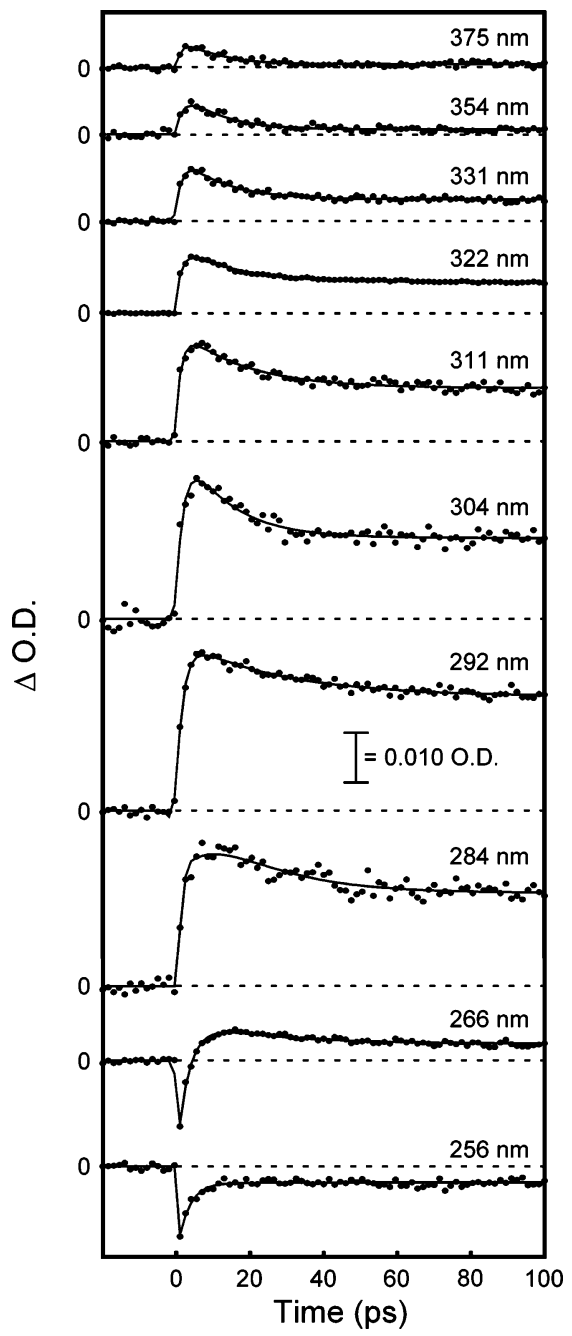

Figure 4. Time-resolved pump-probe dynamics of ClNO dissolved in acetonitrile. Probe wavelengths and optical density scale are indicated. The solid line corresponds to the best fit to the data at a given probe wavelength by a sum of exponentials convolved with the instrument response. Corresponding fit parameters are presented in Table 1.

dichloromethane is complicated by solvent absorption at wavelengths less than $\sim 210 \mathrm{~nm}$. To minimize solvent absorption, a $25 \mu \mathrm{m}$ path length cell was employed in the measurement, and the A-band maximum in dichloromethane was determined to be $213 \mathrm{~nm}\left(46948 \mathrm{~cm}^{-1}\right)$. However, the maximum in chloroform was still difficult to resolve; therefore, an estimate for the absorption maximum was obtained as follows. Assuming that the shape of the A-band in acetonitrile is similar to that for CINO in chloroform, a $2395 \mathrm{~cm}^{-1}$ shift of the absorption in acetonitrile to higher energy in chloroform is required to match the red-edge of the A-band, resulting in a predicted absorption maximum of $206 \mathrm{~nm}\left(48544 \mathrm{~cm}^{-1}\right)$ in chloroform. Solvent dependence of the A-band absorption maximum has been previously observed. ${ }^{66}$ The maxima of the A-band for CINO in the gas phase, cyclohexane, and acetonitrile are located at 196, 206, and $217 \mathrm{~nm}$, respectively, demonstrating a bathochromic shift of the A-band with increasing solvent polarity. For the solvents in the present study, the $E_{\mathrm{T}}(30)$ polarity-scale values are $39.1 \mathrm{kcal} / \mathrm{mol}$ (chloroform), $40.7 \mathrm{kcal} / \mathrm{mol}$ (dichloromethane), and $45.6 \mathrm{kcal} / \mathrm{mol}$ (acetonitrile), ${ }^{70}$ also consistent with a bathchromic shift of the A-band with increasing solvent polarity.

CINO in Acetonitrile. The photoinduced evolution in optical density for CINO dissolved in acetonitrile is presented in Figure 4. To simplify presentation, the results are grouped in the 
TABLE 1: Kinetic Parameters Determined from Analysis of the Pump-Probe Data for CINO Dissolved in Acetonitrile

\begin{tabular}{|c|c|c|c|c|c|c|c|c|}
\hline$\lambda_{\mathrm{pr}}{ }^{a}(\mathrm{~nm})$ & $A_{1}^{b}$ & $\tau_{1}(\mathrm{ps})$ & $A_{2}$ & $\tau_{2}(\mathrm{ps})$ & $A_{3}$ & $\tau_{3}(\mathrm{ps})$ & $A_{4}$ & $\tau_{4}(\mathrm{ps})$ \\
\hline 256 & $-0.69 \pm 0.12^{c}$ & $3.7 \pm 1.0$ & & & & & $0.31 \pm 0.12$ & offset $^{d}$ \\
\hline 266 & $-0.79 \pm 0.14$ & $0.41 \pm 0.17$ & $-0.11 \pm 0.08$ & $7.4 \pm 1.9$ & $0.08 \pm 0.05$ & $23.5 \pm 2.6$ & $0.02 \pm 0.01$ & offset \\
\hline 284 & & & $-0.46 \pm 0.07$ & $5.2 \pm 2.1$ & $0.27 \pm 0.09$ & $16.0 \pm 2.1$ & $0.27 \pm 0.08$ & $>1000$ \\
\hline 292 & & & $-0.28 \pm 0.08$ & $3.4 \pm 1.1$ & $0.23 \pm 0.09$ & $21.3 \pm 5.4$ & $0.49 \pm 0.16$ & $780 \pm 150$ \\
\hline 304 & & & $-0.51 \pm 0.08$ & $2.9 \pm 0.9$ & $0.26 \pm 0.04$ & $11.1 \pm 5.6$ & $0.24 \pm 0.07$ & $800 \pm 90$ \\
\hline 311 & & & $-0.34 \pm 0.12$ & $3.4 \pm 1.8$ & $0.35 \pm 0.06$ & $16.7 \pm 2.3$ & $0.31 \pm 0.07$ & $770 \pm 30$ \\
\hline 322 & & & $-0.22 \pm 0.11$ & $1.7 \pm 0.4$ & $0.40 \pm 0.06$ & $14.2 \pm 1.3$ & $0.39 \pm 0.06$ & $910 \pm 210$ \\
\hline 331 & & & $-0.26 \pm 0.07$ & $2.5 \pm 1.2$ & $0.47 \pm 0.02$ & $12.0 \pm 1.7$ & $0.27 \pm 0.06$ & $620 \pm 60$ \\
\hline 354 & & & $-0.50 \pm 0.13$ & $2.4 \pm 0.3$ & $0.43 \pm 0.10$ & $10.9 \pm 3.1$ & $0.07 \pm 0.03$ & $590 \pm 350$ \\
\hline 375 & & & $-0.48 \pm 0.22$ & $2.1 \pm 0.9$ & $0.44 \pm 0.15$ & $10.7 \pm 4.8$ & $0.08 \pm 0.07$ & $>1000$ \\
\hline
\end{tabular}

${ }^{a}$ Wavelength at which the transient change in optical density was measured. ${ }^{b}$ Amplitudes are normalized such that $\Sigma\left|A_{i}\right|=1 .{ }^{c}$ Errors represent one standard deviation from the mean of all measurements $(\geq 3)$ employed at a given wavelength. ${ }^{d}$ A time constant of 10000 ps was included to represent any persistent offset in optical density at long delay times.

following wavelength regions: $256-266 \mathrm{~nm}, 266-284 \mathrm{~nm}$, and 284-375 nm.

$256 \mathrm{~nm} \leq \lambda_{p r}<266 \mathrm{~nm}$. In this region, a photoinduced reduction in optical density ("depletion") and subsequent recovery is observed. The depletion is instrument-response limited consistent with a loss of ground-state CINO accompanying photolysis. The optical-density depletion partially recovers to reveal a $-3 \pm 1 \mathrm{~m}$ optical density (OD) depletion that persists out to the longest delay times investigated ( $500 \mathrm{ps})$. The recovery in optical density was best fit by a single-exponential having a time constant of $3.7 \pm 1.0 \mathrm{ps}$, with the persistent decrease in optical density reproduced using a long time offset. Time constants determined at this and the other probe wavelengths for CINO dissolved in acetonitrile are provided in Table 1.

$266 \mathrm{~nm} \leq \lambda_{p r}<284 \mathrm{~nm}$. At $266 \mathrm{~nm}$, a pump-induced reduction in optical density is observed at early times consistent with the photoinduced depletion of ground-state CINO. An increase in optical density is observed following the initial depletion, reaching a maximum value of $6 \pm 2 \mathrm{mOD}$ by $\sim 15$ ps. Decay follows until a persistent optical-density change of $\sim 2.5 \mathrm{mOD}$ is reached. The optical-density evolution at $266 \mathrm{~nm}$ was best fit by a sum of three exponentials. The biphasic appearance has an instrument-response limited time constant and a slower constant of $7.4 \pm 1.9$ ps. The third exponential term corresponds to optical-density decay with a time constant of $23.5 \pm 2.6$ ps. Finally, a long-time offset was included to reproduce the persistent increase in optical density.

$284 \mathrm{~nm} \leq \lambda_{p r} \leq 375 \mathrm{~nm}$. At all probe wavelengths in this region, an initial increase in optical density is observed followed by a decay. The optical-density increase was well fit by a single exponential with a time constant that decreases from $7.4 \pm 1.9$ to $2.1 \pm 0.9 \mathrm{ps}$ as the probe wavelength increases from 284 to $375 \mathrm{~nm}$. The decay is biphasic, consisting of a shorter time constant that varies from $21.3 \pm 5.4 \mathrm{ps}$ at $292 \mathrm{~nm}$ to $10.7 \pm$ $4.8 \mathrm{ps}$ at $375 \mathrm{~nm}$, and a longer component of $\sim 1 \mathrm{~ns}$ at all wavelengths. This longer time constant should be considered an estimate due to the limited range of delay times investigated. It is important to note that the maximum change in optical density is observed at shorter delay times as the probe wavelength increases. Specifically, at $284 \mathrm{~nm}$ the optical density reaches a maximum value at $\sim 12 \mathrm{ps,} \mathrm{whereas,} \mathrm{at} 375 \mathrm{~nm}$ a maximum is reached at $\sim 4 \mathrm{ps}$. This evolution in optical density is more readily apparent in two-dimensional contour plot of the transient absorption spectrum presented in Figure 5A. Here, modest blue-shifting and narrowing of the photoproduct band is evident, consistent with photoproduct production followed by vibrational relaxation of this species on the $\sim 20$ ps time scale.

Transient Absorption Spectrum. The absolute change in optical density for CINO dissolved in acetonitrile as a function of probe wavelength measured at specific delay times is presented in Figure 6A. This figure illustrates the two main wavelength regions of interest: the decrease and partial recovery in optical density observed at $256 \mathrm{~nm}$ and the large increase in optical density centered at $\sim 295 \mathrm{~nm}$. The decrease in optical density at $256 \mathrm{~nm}$ occurs immediately after photolysis, consistent with the photoinduced depletion of ground state CINO. The optical density partially recovers to a value of $-3 \mathrm{mOD}$ by 10 ps and remains constant out to the longest delays investigated. This evolution in optical density may be indicative of CINO re-formation by geminate recombination. Time scans employing finer time spaces demonstrate that the maximum optical-density decrease following photolysis is $-42 \pm 5 \mathrm{mOD}$. Comparison of this value to the $-3 \mathrm{mOD}$ of depletion observed at longer times provides an upper limit of $93 \%$ for the amount of the initially depleted CINO that may be re-formed. Optical-density evolution accompanying the vibrational relaxation of re-formed CINO is obscured by the photoproduct absorption band at 295 $\mathrm{nm}$ that is observed within 1 ps of CINO photolysis, and reaches a maximum of $31 \pm 5 \mathrm{mOD}$ by $5 \mathrm{ps}$.

CINO in Chloroform. The photoinduced evolution in optical density for CINO dissolved in chloroform is presented in Figure 7. Consistent with the previous discussion, the results are discussed in the following wavelength regions: $256-266 \mathrm{~nm}$, 266-284 nm, and $284-375 \mathrm{~nm}$.

$256 \mathrm{~nm} \leq \lambda_{p r}<266 \mathrm{~nm}$. The evolution in optical density in this region is characterized by an initial decrease in opticaldensity consistent with photoinduced depletion of ground-state CINO. This is followed by a near complete recovery of optical density, which occurs with a time constant of $8 \pm 1$ ps. A longtime offset in optical density was included to account for the small residual offset in optical density observed at long delays. Table 2 provides the time constants determined at this and other probe wavelengths for CINO dissolved in chloroform.

$266 \mathrm{~nm} \leq \lambda_{p r}<284 \mathrm{~nm}$. Similar to the behavior observed for CINO in acetonitrile, an initial reduction in optical density is observed, consistent with the photoinduced depletion of ground-state CINO. The pump-induced depletion is followed by an increase in optical density that reaches a maximum of 10 mOD by $\sim 25$ ps. A decay in optical density is then observed until a value of $\sim 1 \mathrm{mOD}$ is reached. The optical-density evolution was best fit with a sum of two exponentials, with the increase in optical density occurring with a time constant of $10.1 \pm 1.7 \mathrm{ps}$ and subsequent decay with a time constant of $36.6 \pm 21.1$ ps. Finally, a long-time offset was included in the fitting procedure to reproduce the persistent increase in optical density.

$284 \mathrm{~nm} \leq \lambda_{p r} \leq 375 \mathrm{~nm}$. The evolution observed in this wavelength region is characterized by an initial increase in optical density followed by a biphasic decay. The initial optical- 

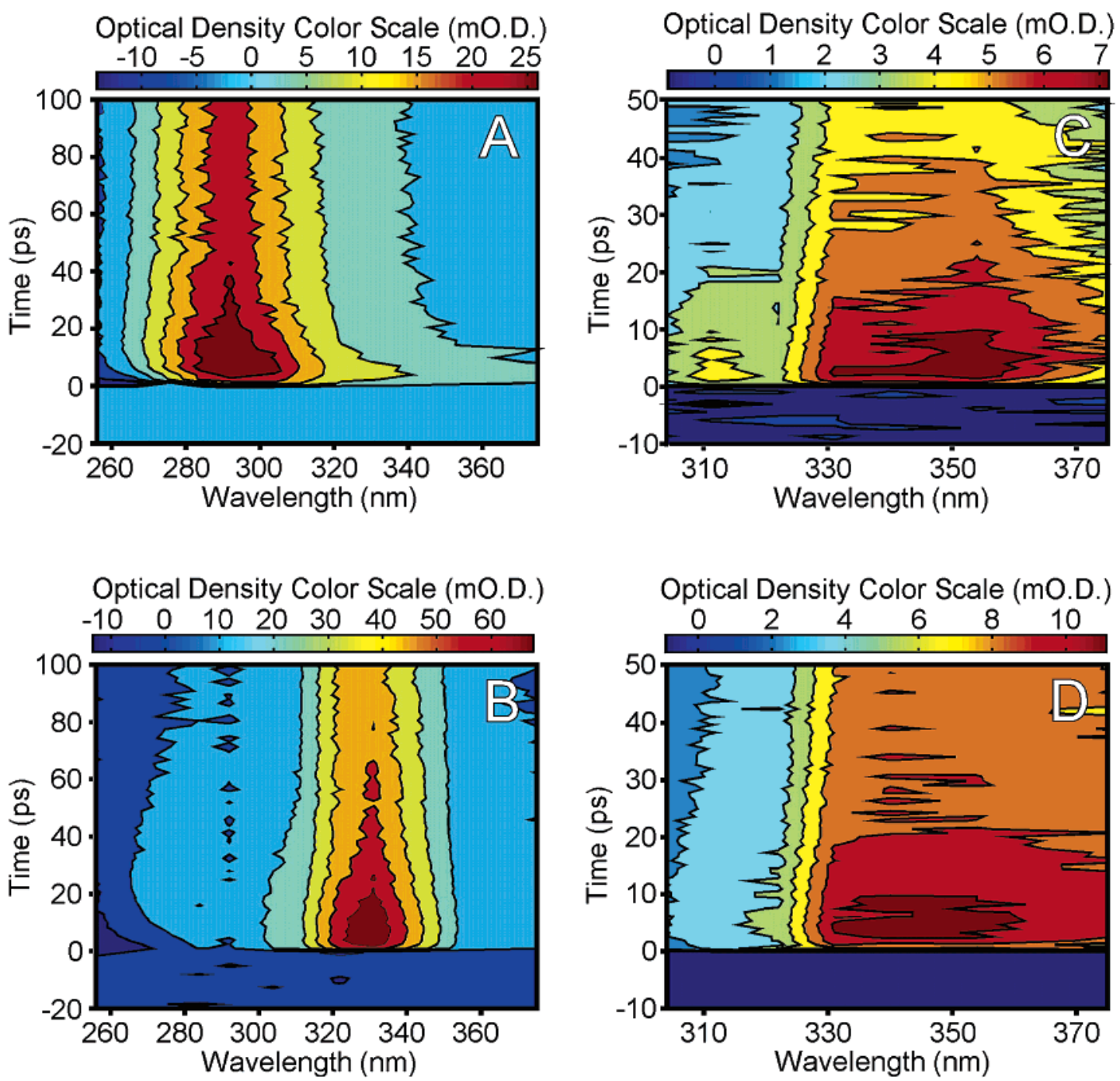

Figure 5. Contour plots of the transient absorption spectrum of (A) $\mathrm{ClNO}$ dissolved in acetonitrile, (B) $\mathrm{ClNO}$ dissolved in chloroform, (C) MeOCl dissolved in dichloromethane and (D) CINO dissolved in dichloromethane. The absolute change in optical density is indicated by the contour lines, with the color scale shown above the each plot. Photolysis energies were $10.0 \mu \mathrm{J}$ in acetonitrile and chloroform, and $0.54 \mu \mathrm{J}$ for $\mathrm{ClNO}$ and $\mathrm{MeOCl}$ in dichloromethane.

density increase was fit by a single exponential with time constants ranging from $3.2 \pm 1.1 \mathrm{ps}$ at $331 \mathrm{~nm}$ to $9.9 \pm 1.8 \mathrm{ps}$ at $284 \mathrm{~nm}$. The shortest decay time constant varied from 10.0 $\pm 4.2 \mathrm{ps}$ at $375 \mathrm{~nm}$ to $34.4 \pm 11.4 \mathrm{ps}$ at $304 \mathrm{~nm}$. The longer decay time constant was $\sim 1 \mathrm{~ns}$ at all probe wavelengths, which should be viewed as an estimate given the limited delay-times investigated. In contrast to the behavior observed in acetonitrile, the photoproduct absorption band demonstrates limited spectral evolution as illustrated in the contour plot of the optical-density evolution presented in Figure 5B. Blue-edge enhancement of the photoproduct absorption band is apparent at early times, however, significant early-time optical-density enhancement and decay on red-shifting of the absorption maximum consistent with vibrational relaxation is not observed.

Transient Absorption Spectrum. The transient absorption spectrum of CINO dissolved in chloroform is presented in Figure 6B. Two main wavelength regions of interest are evident: the initial decrease and recovery in optical density observed at 256 $\mathrm{nm}$ and the large increase in optical density observed at 331 $\mathrm{nm}$. Photolysis results in an initial decrease in optical density consistent with depletion of ground-state CINO. Experiments with finer time spacings demonstrate that the magnitude depletion amplitude is $-21 \pm 6 \mathrm{mOD}$. The depletion recovers to zero within the error of the measurement $(3 \mathrm{mOD})$ and remains constant out to the longest delays. The photoproduct absorption band centered at $331 \mathrm{~nm}$ appears within $1 \mathrm{ps}$ of CINO photolysis reaching a maximum of $81 \pm 12 \mathrm{mOD}$ by $3 \mathrm{ps}$. The absence of residual depletion associated with ground-state $\mathrm{CINO}$ prohibits defining a lower limit for the geminate recombination quantum yield; however, the magnitude of the photoproduct band optical density is 4 times larger than the reduction in optical-density associated with CINO depletion such that the photoproduct must have a molar absorptivity that is significantly greater than that of $\mathrm{ClNO}$ at $256 \mathrm{~nm}$.

Cl:Solvent Charge-Transfer Complex Study. To explore the possibility that the photoproduct band observed following CINO photolysis corresponds to the $\mathrm{Cl}$ :solvent charge-transfer complex, photochemical studies of $\mathrm{MeOCl}$ were performed. Recent work by Crim and co-workers has established that photolysis of this species at $266 \mathrm{~nm}$ results in the production of $\mathrm{Cl}$ such that $\mathrm{MeOCl}$ is a convenient photochemical $\mathrm{Cl}$ precursor. ${ }^{67}$ Unfortunately, the instability of $\mathrm{MeOCl}$ in chloroform prevented its use in this solvent. Instead, the $\mathrm{Cl}$ :solvent charge-transfer study was performed in dichloromethane. The similarity of dichloromethane and chloroform in terms of molecular structure and solvent polarity, as well as the preexisting photochemical studies in this solvent make dichloromethane an attractive alternative solvent for study. A contour plot of the 


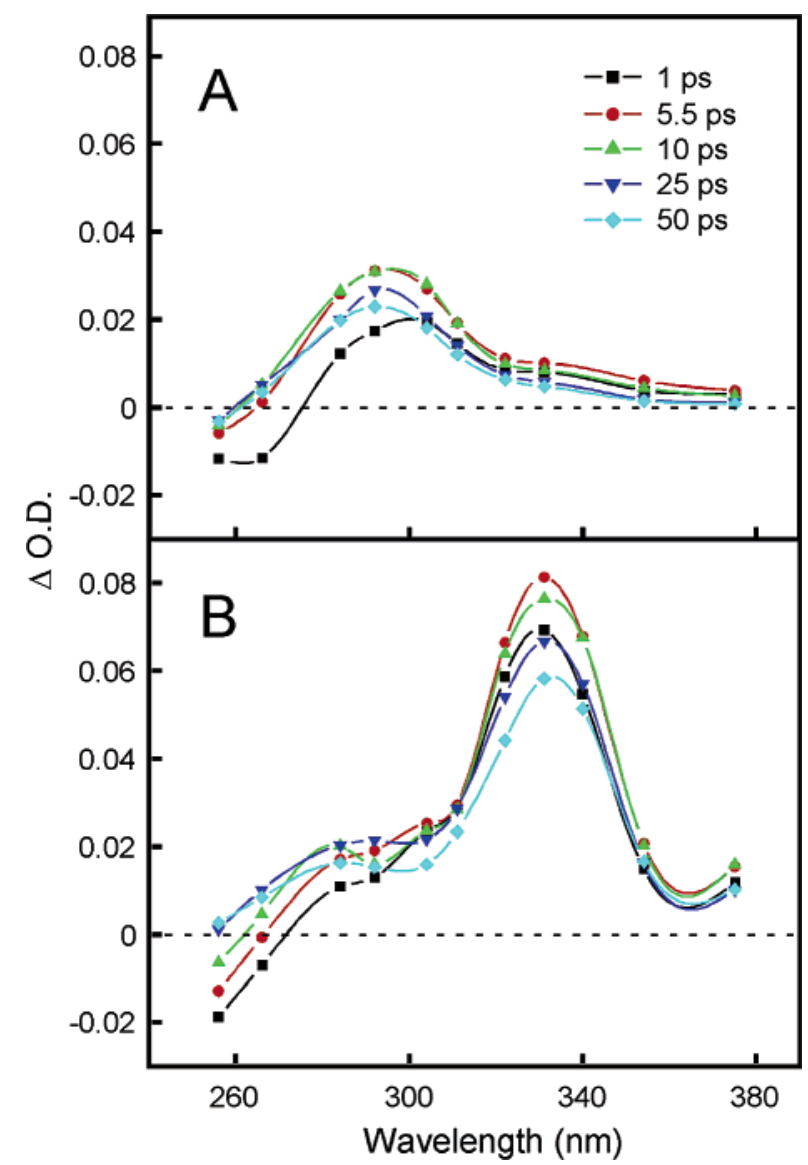

Figure 6. Transient absorption spectrum of (A) ClNO dissolved in acetonitrile and (B) CINO dissolved in chloroform. The time delay for each spectrum is given in the figure.

pump - probe dynamics observed following $\mathrm{MeOCl}$ photoexcitation in dichloromethane is presented in Figure 5C. At all probe wavelengths an instrument-response-limited increase in optical density is observed followed by a longer-time optical-density increase that occurs with a time constant that varies from 0.99 $\pm 0.07 \mathrm{ps}$ at $311 \mathrm{~nm}$ to $2.9 \pm 0.8$ at $375 \mathrm{~nm}$. After reaching a maximum, a decay in optical density is observed with a time constant that varies from $20.0 \pm 7.1 \mathrm{ps}$ at $340 \mathrm{~nm}$ to $41.1 \pm$ $11.2 \mathrm{ps}$ at $304 \mathrm{~nm}$. A long-time offset in optical density follows and persists out to the longest delays investigated (50 ps). The time constants measured at the individual probe wavelengths are provided in Table 3 . The absorption band of the chargetransfer complex is broad and centered at $\sim 340 \mathrm{~nm}$, reaching a maximum optical density change of $7 \mathrm{mOD}$ by $\sim 5 \mathrm{ps}$.

The pump-probe dynamics for CINO dissolved in dichloromethane were measured under photolysis conditions identical to those employed for $\mathrm{MeOCl}$, and a contour plot of the pumpprobe dynamics in this solvent is presented in Figure 5D. The time constants for optical-density evolution determined at the individual probe wavelengths are provided in Table 4. Following photoexcitation, an instrument-response limited increase in optical density is observed followed by an additional longertime increase that occurs with a time constant that varies from $1.6 \pm 0.4 \mathrm{ps}$ at $340 \mathrm{~nm}$ to $4.3 \pm 3.0 \mathrm{ps}$ at $304 \mathrm{~nm}$. A subsequent decay in optical density is observed, occurring with a time constant that varies from $12.8 \pm 3.8$ ps at $322 \mathrm{~nm}$ to $25.6 \pm$ $13.5 \mathrm{ps}$ at $304 \mathrm{~nm}$ to reveal an optical-density offset that is constant out to the longest delays investigated. Comparison of the pump-probe kinetics for $\mathrm{MeOCl}$ and $\mathrm{ClNO}$ in dichloromethane demonstrates that photoproduct formation for $\mathrm{ClNO}$

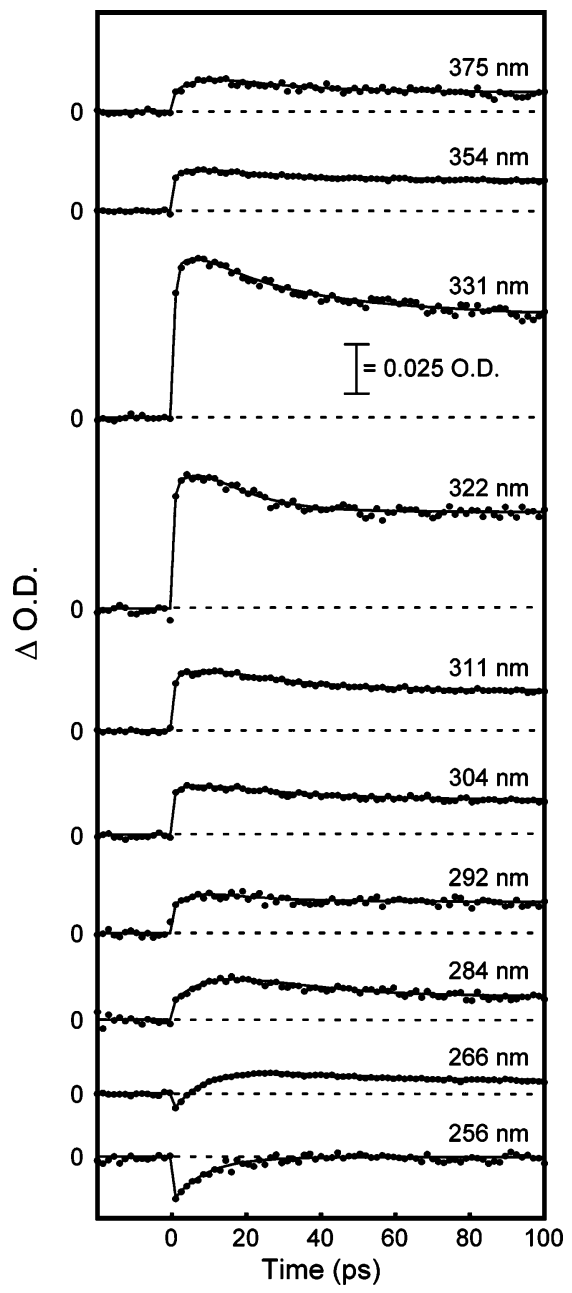

Figure 7. Time-resolved pump-probe dynamics of ClNO dissolved in chloroform. Probe wavelengths and optical density scale are indicated. The solid line corresponds to the best fit to the data at a given probe wavelength by a sum of exponentials convolved with the instrument response. Corresponding fit parameters are presented in Table 2.

is slower, and the decay in optical density assignable to the photoproduct is more rapid than that observed for the $\mathrm{Cl}$ :solvent charge-transfer complex produced following $\mathrm{MeOCl}$ photolysis.

In summary, the results presented here indicate that in all solvents CINO photolysis results in the production of at least one photoproduct that persists out to $500 \mathrm{ps}$. The photoproduct band has a maximum of $295 \mathrm{~nm}$ in acetonitrile, but in chloroform and dichloromethane the maximum is shifted to 330 $\mathrm{nm}$. Photolysis of $\mathrm{MeOCl}$ in dichloromethane demonstrates that the $\mathrm{Cl}$ :solvent charge-transfer complex in this solvent has an absorption maximum close to $330 \mathrm{~nm}$ supporting assignment of the CINO photoproduct in chloroform and dichloromethane to the $\mathrm{Cl}$ :solvent charge-transfer complex. However, the photoproduct band shapes, the kinetics for optical-density evolution, and the magnitude of the optical-density increase corresponding to photoproduct formation differ significantly between CINO and $\mathrm{MeOCl}$ under identical photolysis conditions complicating the assignment of the $\mathrm{CINO}$ photoproduct to the $\mathrm{Cl}$ :solvent complex. The maximum change in optical density of the CINO photoproduct is solvent dependent, with the optical density being 2.7 times larger in chloroform compared to acetonitrile (Figure $6)$. Finally, the maximum optical density change of the CINOphotoproduct peak in chloroform is 4 times larger than the decrease in optical density due to photoexcitation of CINO, 
TABLE 2: Kinetic Parameters Determined from Analysis of the Pump-Probe Data for CINO Dissolved in Chloroform

\begin{tabular}{|c|c|c|c|c|c|c|c|c|}
\hline$\lambda_{\mathrm{pr}}^{a}(\mathrm{~nm})$ & $A_{1}{ }^{b}$ & $\tau_{1}(\mathrm{ps})$ & $A_{2}$ & $\tau_{2}(\mathrm{ps})$ & $A_{3}$ & $\tau_{3}(\mathrm{ps})$ & $A_{4}$ & $\tau_{4}(\mathrm{ps})$ \\
\hline 256 & $-0.92 \pm 0.06^{c}$ & $7.9 \pm 1.0$ & & & & & $-0.04 \pm 0.08$ & offset $^{d}$ \\
\hline 266 & & & $-0.62 \pm 0.03$ & $10.1 \pm 1.7$ & $0.29 \pm 0.02$ & $36.6 \pm 21.1$ & $0.09 \pm 0.03$ & offset \\
\hline 284 & & & $-0.44 \pm 0.06$ & $9.9 \pm 1.8$ & $0.37 \pm 0.04$ & $16.8 \pm 5.0$ & $0.18 \pm 0.09$ & $7600 \pm 4200$ \\
\hline 292 & & & $-0.30 \pm 0.08$ & $7.2 \pm 4.7$ & $0.34 \pm 0.10$ & $27.2 \pm 13.4$ & $0.36 \pm 0.16$ & $1430 \pm 580$ \\
\hline 304 & & & $-0.23 \pm 0.10$ & $4.9 \pm 3.4$ & $0.32 \pm 0.07$ & $34.4 \pm 11.4$ & $0.45 \pm 0.11$ & $980 \pm 470$ \\
\hline 311 & & & $-0.43 \pm 0.05$ & $6.7 \pm 3.9$ & $0.29 \pm 0.03$ & $16.5 \pm 6.3$ & $0.27 \pm 0.07$ & $730 \pm 190$ \\
\hline 322 & & & $-0.19 \pm 0.05$ & $3.2 \pm 1.6$ & $0.24 \pm 0.05$ & $12.6 \pm 6.9$ & $0.56 \pm 0.09$ & $880 \pm 440$ \\
\hline 331 & & & $-0.21 \pm 0.05$ & $3.2 \pm 1.0$ & $0.25 \pm 0.03$ & $19.2 \pm 6.8$ & $0.53 \pm 0.07$ & $780 \pm 490$ \\
\hline 354 & & & $-0.30 \pm 0.04$ & $5.4 \pm 1.5$ & $0.29 \pm 0.04$ & $12.2 \pm 3.7$ & $0.41 \pm 0.08$ & $1100 \pm 430$ \\
\hline 375 & & & $-0.47 \pm 0.04$ & $6.7 \pm 3.1$ & $0.48 \pm 0.03$ & $10.0 \pm 4.2$ & $0.10 \pm 0.06$ & $1250 \pm 1240$ \\
\hline
\end{tabular}

${ }^{a}$ Wavelength at which the transient change in optical density was measured. ${ }^{b}$ Amplitudes are normalized such that $\Sigma\left|A_{i}\right|=1 .{ }^{c}$ Errors represent one standard deviation from the mean of all measurements $(\geq 3)$ employed at a given wavelength. ${ }^{d}$ A time constant of 10000 ps was included to represent any persistent offset in optical density at long delay times.

TABLE 3: Kinetic Parameters Determined from Analysis of the Pump-Probe Data for $\mathrm{CH}_{3} \mathrm{OCl}$ Dissolved in Dichloromethane

\begin{tabular}{|c|c|c|c|c|c|c|}
\hline$\lambda_{\mathrm{pr}}{ }^{a}(\mathrm{~nm})$ & $A_{1}{ }^{b}$ & $\tau_{1}(\mathrm{ps})$ & $A_{2}$ & $\tau_{2}(\mathrm{ps})$ & $A_{3}$ & $\tau_{3}(\mathrm{ps})$ \\
\hline 304 & $-0.41 \pm 0.28^{c}$ & $1.48 \pm 0.48$ & $0.32 \pm 0.17$ & $41.1 \pm 11.2$ & $0.28 \pm 0.15$ & offset $^{d}$ \\
\hline 311 & $-0.19 \pm 0.04$ & $0.99 \pm 0.07$ & $0.55 \pm 0.16$ & $40.0 \pm 23.4$ & $0.26 \pm 0.17$ & offset \\
\hline 322 & $-0.22 \pm 0.06$ & $1.14 \pm 0.20$ & $0.44 \pm 0.14$ & $35.7 \pm 21.6$ & $0.34 \pm 0.12$ & offset \\
\hline 331 & $-0.36 \pm 0.01$ & $1.04 \pm 0.15$ & $0.36 \pm 0.10$ & $33.5 \pm 10.4$ & $0.29 \pm 0.09$ & offset \\
\hline 340 & $-0.24 \pm 0.07$ & $2.02 \pm 0.77$ & $0.31 \pm 0.04$ & $20.0 \pm 7.1$ & $0.47 \pm 0.06$ & offset \\
\hline 354 & $-0.32 \pm 0.04$ & $1.34 \pm 0.41$ & $0.36 \pm 0.02$ & $34.8 \pm 7.7$ & $0.26 \pm 0.15$ & offset \\
\hline 375 & $-0.30 \pm 0.20$ & $2.94 \pm 0.78$ & $0.47 \pm 0.26$ & $21.5 \pm 3.2$ & $0.23 \pm 0.16$ & offset \\
\hline
\end{tabular}

${ }^{a}$ Wavelength at which the transient change in optical density was measured. ${ }^{b}$ Amplitudes are normalized such that $\Sigma\left|A_{i}\right|=1 .{ }^{c}$ Errors represent one standard deviation from the mean of all measurements $(\geq 3)$ employed at a given wavelength. ${ }^{d} \mathrm{~A}$ time constant of 10000 ps was included to represent any persistent offset in optical density at long delay times.

TABLE 4: Kinetic Parameters Determined from Analysis of the Pump-Probe Data for CINO Dissolved in Dichloromethane

\begin{tabular}{|c|c|c|c|c|c|c|}
\hline$\lambda_{\mathrm{pr}^{a}}(\mathrm{~nm})$ & $A_{1}^{b}$ & $\tau_{1}(\mathrm{ps})$ & $A_{2}$ & $\tau_{2}(\mathrm{ps})$ & $A_{3}$ & $\tau_{3}(\mathrm{ps})$ \\
\hline 304 & $-0.27 \pm 0.05^{c}$ & $4.3 \pm 3.0$ & $0.37 \pm 0.13$ & $25.6 \pm 13.5$ & $0.36 \pm 0.15$ & offset $^{d}$ \\
\hline 311 & $-0.26 \pm 0.03$ & $3.4 \pm 0.9$ & $0.31 \pm 0.04$ & $14.0 \pm 5.0$ & $0.36 \pm 0.18$ & offset \\
\hline 322 & $-0.19 \pm 0.08$ & $4.6 \pm 1.6$ & $0.32 \pm 0.08$ & $12.8 \pm 3.8$ & $0.48 \pm 0.14$ & offset \\
\hline 331 & $-0.19 \pm 0.11$ & $3.7 \pm 2.4$ & $0.29 \pm 0.06$ & $22.6 \pm 10.5$ & $0.52 \pm 0.14$ & offset \\
\hline 340 & $-0.31 \pm 0.07$ & $1.6 \pm 0.4$ & $0.27 \pm 0.06$ & $18.2 \pm 6.6$ & $0.42 \pm 0.07$ & offset \\
\hline 354 & $-0.31 \pm 0.02$ & $2.0 \pm 0.5$ & $0.22 \pm 0.02$ & $14.0 \pm 3.5$ & $0.47 \pm 0.04$ & offset \\
\hline 375 & $-0.33 \pm 0.03$ & $2.7 \pm 0.7$ & $0.27 \pm 0.06$ & $16.9 \pm 7.4$ & $0.41 \pm 0.06$ & offset \\
\hline 400 & $-0.35 \pm 0.04$ & $11.3 \pm 2.1$ & $0.57 \pm 0.07$ & $22.9 \pm 2.5$ & $0.08 \pm 0.04$ & offset \\
\hline
\end{tabular}

${ }^{a}$ Wavelength at which the transient change in optical density was measured. ${ }^{b}$ Amplitudes are normalized such that $\Sigma\left|A_{i}\right|=1 .{ }^{c}$ Errors represent one standard deviation from the mean of all measurements $(\geq 3)$ employed at a given wavelength. ${ }^{d}$ A time constant of 10000 ps was included to represent any persistent offset in optical density at long delay times.

suggesting that the molar absorptivity of the photoproduct at $330 \mathrm{~nm}$ is at least 4 times larger than that of CINO at $256 \mathrm{~nm}$ (Figure 6).

\section{Discussion}

One of the main goals for this study is to examine the photochemistry of solution-phase CINO. As mentioned in the Introduction, photochemical studies of gaseous CINO employing wavelengths resonant with the A-band have shown that $\mathrm{Cl}$ and NO formation is the dominant photochemical pathway. ${ }^{25,36,39-56}$ In contrast, the structural isomer $(\mathrm{ClON})$ is the only photoproduct observed in low-temperature matrix studies. ${ }^{63,64}$ The results presented here represent the first detailed measurements of CINO photochemistry in solution. The experimentally observed opticaldensity evolution that occurs following CINO photolysis demonstrates that a photoproduct is formed that has an absorption maximum of $295 \mathrm{~nm}$ in acetonitrile and $330 \mathrm{~nm}$ in chloroform. There are three possible assignments for this photoproduct: $\mathrm{NO}$, the $\mathrm{Cl}$ :solvent charge-transfer complex, and the photoisomer $\mathrm{ClON}$. The absorption band of gas-phase NO consists of a series of discrete rotation bands, which begin at about $230 \mathrm{~nm}$ and continue into the far UV. ${ }^{71}$ Because the absorption of NO is well removed from the wavelength region of interest, this species most likely does not contribute to the optical density evolution observed in this experiment and is subsequently removed from consideration as the photoproduct.

Dissociation is the dominant photochemical pathway for gaseous $\mathrm{CINO}$; therefore, it is reasonable to expect that $\mathrm{Cl}$ is produced following CINO photolysis in solution. In solution, $\mathrm{Cl}$ will interact with the solvent to form the $\mathrm{Cl}$ :solvent chargetransfer complex, with the absorption band maximum of this species correlating with the ionization potential of the solvent. ${ }^{72}$ The absorption maximum for the $\mathrm{Cl}$ :chloroform charge-transfer complex is at $330 \mathrm{~nm} .{ }^{72}$ This wavelength is essentially identical to the CINO photoproduct absorption-band maximum in chloroform supporting assignment of the photoproduct to the $\mathrm{Cl}$ : solvent charge-transfer complex. To test this assignment, we performed a photochemical study of $\mathrm{MeOCl}$ dissolved in a similar solvent, dichloromethane. $\mathrm{MeOCl}$ is a convenient photochemical precursor for $\mathrm{Cl}{ }^{67,73,74}$ Furthermore, chloroform and dichloromethane have essentially the same ionization potential (11.37 and $11.32 \mathrm{eV})$ such that the location of the $\mathrm{Cl}$ :solvent charge-transfer band in these solvents should be almost identical. ${ }^{72}$ Finally, the pump-probe dynamics of $\mathrm{MeOCl}$ in dichloromethane have previously been investigated by Crim and co-workers, and they found that photolysis of $\mathrm{MeOCl}$ at 
$266 \mathrm{~nm}$ resulted in formation of the $\mathrm{Cl}$ :solvent charge-transfer complex with an absorption maximum of $330 \mathrm{~nm} .{ }^{67}$ The pumpprobe dynamics for $\mathrm{MeOCl}$ dissolved in dichloromethane were compared to those observed for CINO dissolved in this same solvent and under identical photolysis conditions. The photoproduct absorption maxima for $\mathrm{MeOCl}$ and $\mathrm{ClNO}$ are essentially identical (Figure 5C,D), supporting assignment of the CINO photoproduct to the $\mathrm{Cl}$ :solvent charge-transfer complex. However, the kinetics, magnitude of the optical-density change, and the band shapes associated with the photoproduct differ significantly between $\mathrm{CINO}$ and $\mathrm{MeOCl}$. Specifically, for CINO photoproduct formation is slower, and decay of this species is more rapid in comparison to $\mathrm{MeOCl}$ (Tables 3 and 4). Also, for CINO the long-time increase in optical density is twice as large as that observed for $\mathrm{MeOCl}$. Both of these observations call into question assignment of the CINO photoproduct in chloroform and dichloromethane to the $\mathrm{Cl}$ :solvent chargetransfer complex.

To further investigate the assignment of the $\mathrm{Cl}$ :solvent chargetransfer complex as the CINO photoproduct, we attempted to model the transient absorption spectrum of $\mathrm{ClNO}$ in chloroform by assuming that $\mathrm{Cl}$ production is the dominant photochemical pathway. In the model we also assume that the surrounding solvent shell provides a barrier for some of the departing photofragments, resulting in geminate recombination to re-form the parent molecule, with $\mathrm{Cl}$ photofragments that escape the solvent cage resulting in formation of the charge-transfer complex. The photolysis-induced change in optical density $(\Delta \mathrm{OD}(\lambda))$ can be expressed as

$$
\begin{aligned}
& \Delta \mathrm{OD}(\lambda)= \\
& \quad b\left\{\epsilon_{\mathrm{Cl}}(\lambda)[\mathrm{Cl}]-\epsilon_{\mathrm{ClNO}}(\lambda)\left([\mathrm{ClNO}]_{\mathrm{ex}}-[\mathrm{ClNO}]_{\mathrm{ref}}\right)\right\}
\end{aligned}
$$

where $b$ is the path length and $\epsilon_{\mathrm{Cl}}(\lambda)$ and $\epsilon_{\mathrm{CINO}}(\lambda)$ are the wavelength-dependent molar absorptivities of the $\mathrm{Cl}$ :solvent charge-transfer complex and $\mathrm{CINO}$, respectively. The concentration of the $\mathrm{Cl}$ :solvent charge-transfer complex is given by $[\mathrm{Cl}]$. The concentration of CINO re-formed following photolysis is given by $[\mathrm{ClNO}]_{\mathrm{ref}}$, and the concentration of initially photoexcited $\mathrm{ClNO}$ is given by $[\mathrm{ClNO}]_{\mathrm{ex}}$. The amount of $\mathrm{Cl}$ produced and the amount of CINO that geminately recombines is equal to the total amount of the initially photoexcited CINO:

$$
[\mathrm{ClNO}]_{\mathrm{ex}}=[\mathrm{ClNO}]_{\mathrm{ref}}+[\mathrm{Cl}]
$$

Applying this constraint to eq 1 and using the definition of the quantum yield of chlorine production $\left(\Phi_{\mathrm{Cl}}=[\mathrm{Cl}] /[\mathrm{ClNO}]_{\mathrm{ex}}\right)$, the following expression for the change in optical density is obtained:

$$
\Delta \mathrm{OD}(\lambda)=b\left\{\epsilon_{\mathrm{Cl}}(\lambda)-\epsilon_{\mathrm{ClNO}}(\lambda)\right\} \Phi_{\mathrm{Cl}}[\mathrm{ClNO}]_{\mathrm{ex}}
$$

Application of eq 3 requires knowledge of the molar absorptivity of the $\mathrm{Cl}$ :solvent charge-transfer complex, however these values are not known for $\mathrm{Cl}$ :chloroform. Therefore, approximate values were derived as follows. The absorption band of the $\mathrm{Cl}$ :water charge-transfer complex has an absorption maximum at $310 \mathrm{~nm}$ (32 $258 \mathrm{~cm}^{-1}$ ); therefore, this band was shifted by $1955 \mathrm{~cm}^{-1}$ to lower energy to match the absorption maximum of the $\mathrm{Cl}$ : chloroform complex of $330 \mathrm{~nm}\left(30303 \mathrm{~cm}^{-1}\right) .{ }^{72}$ The Cl:water and $\mathrm{Cl}$ :dichloromethane charge-transfer complexes have similar bandwidths supporting this approximation. ${ }^{67,75} \mathrm{Next}$, the concentration of initially photolyzed CINO ([ClNO $\left.]_{\mathrm{ex}}\right)$ was determined as follows. The maximum depletion observed at $256 \mathrm{~nm}$ in chloroform was $-21 \mathrm{mOD}$, the cell path length in this solvent

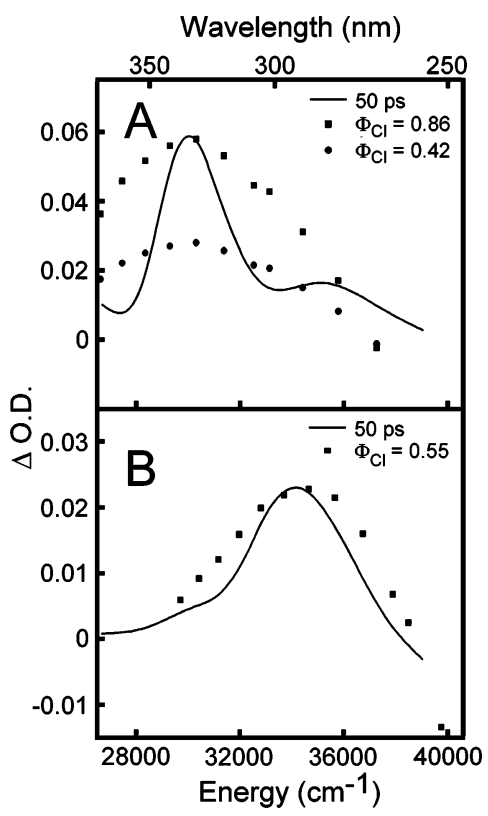

Figure 8. Calculation of the transient absorption spectrum of (A) CINO dissolved in chloroform and (B) ClNO dissolved in acetonitrile. The calculation is based on a photochemical mechanism involving only geminate recombination and $\mathrm{Cl}$ production, as described in the text. The calculated spectra, quantified in terms of the chlorine quantum yield $\left(\Phi_{\mathrm{Cl}}\right)$, are compared to the measured transient absorption spectra taken with a $50 \mathrm{ps}$ time delay.

was $0.095 \mathrm{~cm}$, and $\epsilon_{\mathrm{ClNO}}$ at $256 \mathrm{~nm}$ was $1197 \mathrm{M}^{-1} \mathrm{~cm}^{-1}$. Using these quantities and Beer's law, $[\mathrm{ClNO}]_{\mathrm{ex}}=1.8 \times 10^{-4} \mathrm{M}$ corresponding to $4 \%$ depletion. Beginning with this concentration as an upper limit for $\mathrm{Cl}$ production (i.e., complete cage escape), we explored various values of $\Phi_{\mathrm{Cl}}$ in an attempt to reproduce the transient absorption spectrum. Figure 8A presents a comparison of the calculated and experimental optical-density change observed at $50 \mathrm{ps}$ delay. The figure demonstrates that the magnitude of the optical-density increase can be reproduced by assuming $\Phi_{\mathrm{Cl}}=0.86$; however, the breadth of the $\mathrm{Cl}$ :solvent charge-transfer band is significantly greater than that of the CINO photoproduct. There are a few issues that should be considered at this point. First, we have assumed a maximum molar absorptivity value for the $\mathrm{Cl}$ :chloroform charge-transfer complex of $4000 \mathrm{M}^{-1} \mathrm{~cm}^{-1}$, consistent with the corresponding value in water. $^{75}$ However, the $\mathrm{Cl}$ :benzene charge-transfer complex has a maximum molar absorptivity value of only 2000 $\mathrm{M}^{-1} \mathrm{~cm}^{-1} ;{ }^{76}$ thus, the molar absorptivity of water may represent an upper limit for charge-transfer complexes. Also, we have assumed that the $\mathrm{Cl}$ :solvent complex absorption bandwidths are identical for water and chloroform. However, the bandwidths vary from $\sim 4000 \mathrm{~cm}^{-1}$ to $\sim 10000 \mathrm{~cm}^{-1}$ (full width halfmaximum) depending on solvent. ${ }^{72,77}$ In comparison, the bandwidth of the CINO photoproduct band is only $\sim 2600 \mathrm{~cm}^{-1}$. Therefore, assignment of the CINO photoproduct in chloroform to the $\mathrm{Cl}$ :solvent charge-transfer complex is far from clear.

To further explore the extent of $\mathrm{Cl}$ production following CINO photolysis, an identical comparison of the predicted and experimental optical-density change for $\mathrm{CINO}$ dissolved in acetonitrile was performed. As with chloroform, the molar absorptivity values are not known for the $\mathrm{Cl}$ :acetonitrile chargetransfer complex; therefore, the values for the $\mathrm{Cl}$ :water complex were again employed. Using a linear correlation between the $\mathrm{Cl}$ :solvent charge-transfer band maxima and the solvent ionization potential ${ }^{72}$ and the literature value for the ionization potential for acetonitrile $(12.20 \mathrm{eV})$, we calculated the absorption 
maximum to be $275 \mathrm{~nm}\left(36364 \mathrm{~cm}^{-1}\right)$. However, a better fit to the data was obtained using an absorption maximum of 280 $\mathrm{nm}\left(35714 \mathrm{~cm}^{-1}\right)$. The maximum depletion observed at 256 $\mathrm{nm}$ was $-42 \mathrm{mOD}$, the path length used for the studies of CINO in acetonitrile was $0.2 \mathrm{~cm}$, and the CINO molar absorptivity at $256 \mathrm{~nm}$ is $3508 \mathrm{M}^{-1} \mathrm{~cm}^{-1}$. Therefore, $[\mathrm{ClNO}]_{\mathrm{ex}}=6.0 \times 10^{-5}$ $\mathrm{M}$ corresponding to $4.6 \%$ depletion. Figure $8 \mathrm{~B}$ presents the comparison between the predicted and measured optical-density change for $\mathrm{CINO}$ in acetonitrile at $50 \mathrm{ps}$ delay. In contrast to chloroform, reasonably good agreement was obtained by assuming $\Phi_{\mathrm{Cl}}=0.55$. The ability of the calculation to reproduce the measured optical-density change provides support for the dominance of the $\mathrm{Cl}$ and $\mathrm{NO}$ photochemical channel in acetonitrile. According to the calculation, the maximum change in optical density due to the CINO photoproduct corresponds to $\Phi_{\mathrm{Cl}}=0.75$; however, the apparent quantum yield decreases to 0.55 by $50 \mathrm{ps}$ following photolysis. The decay of chlorine may be due to diffusive geminate recombination, consistent with previous studies of the dynamics of $\mathrm{Cl}$ :solvent charge-transfer complexes. ${ }^{67,78}$

The model described above assumes that only $\mathrm{Cl}$ and $\mathrm{NO}$ are produced; therefore, the possibility of other photochemical channels being operative in this solvent was considered. It remains reasonable to expect that the production of $\mathrm{Cl}$ and $\mathrm{NO}$ occurs in this solvent given the dominance of this photoproduct channel in the gas phase. Furthermore, Figure 8A demonstrates that there is a broad low-lying optical density increase that could be consistent with formation of the $\mathrm{Cl}$ :solvent charge-transfer complex $\left(\Phi_{\mathrm{Cl}}=0.42\right)$. However, the species responsible for the main photoproduct band in chloroform remains in question. The final potential photoproduct to consider is the structural isomer, $\mathrm{ClON}$. The production of $\mathrm{ClON}$ following $\mathrm{ClNO}$ photolysis in low-temperature $\mathrm{Ar}$ and $\mathrm{N}_{2}$ matrixes has been observed. ${ }^{63,64}$ In this previous study, the absorption spectrum of ClNO before and after photolysis was obtained, and the formation of a new broad absorption band centered at $417 \mathrm{~nm}$ was observed and assigned to $\mathrm{ClON} .{ }^{64}$ Given this observation, assignment of the solution-phase photoproduct to $\mathrm{ClON}$ requires that the absorption maximum of this species undergo an $85 \mathrm{~nm}$ shift in chloroform relative to low-temperature matrixes. How reasonable is it to expect such a large shift in the absorption maximum of this species?

Insight into the environmental sensitivity of the $\mathrm{ClON}$ absorption spectrum can be obtained by considering the behavior of the parent species, CINO. Experimental and theoretical studies have shown that the absorption spectrum of CINO is sensitive to the local environment. For gaseous CINO the A-band maximum occurs at $196 \mathrm{~nm}$, and in acetonitrile the maximum shifts to $217 \mathrm{~nm} .{ }^{65,66}$ This behavior was attributed to the environmental dependence of the $\mathrm{NCl}$ bond length. ${ }^{66}$ Calculations indicate that in $\mathrm{ClNO}$, the $\mathrm{NCl}$ bond length $(1.98 \AA)$ is elongated, whereas the NO bond length $(1.13 \AA)$ is close to that of molecular NO (1.151 $\AA$ ), suggesting that the $\mathrm{Cl}$ is only loosely bound to NO. ${ }^{79}$ Furthermore, it has been suggested that nitrosyl halides are best described by an ionic structure corresponding to $\mathrm{X}^{-}(\mathrm{X}=\mathrm{F}, \mathrm{Cl}, \mathrm{Br})$ interacting with $\mathrm{NO}^{+} .80,81$ Assuming substantial ionic character of the CIN bond in CINO, the absorption spectrum of this species should be sensitive to the environment. Environmental sensitivity of the CIN bond length is reflected by variation of the CINO vibrational frequencies with solvent. Specifically, the NO-stretch fundamental transition $\left(v_{1}\right)$ does not change significantly between gasphase $\left(1799.7 \mathrm{~cm}^{-1}\right)$ and Ar matrixes $\left(1805 \mathrm{~cm}^{-1}\right)$; however, the bend and $\mathrm{CIN}$ fundamental transitions shift from $596 \mathrm{~cm}^{-1}$ $\left(v_{2}\right)$ and $332 \mathrm{~cm}^{-1}\left(v_{3}\right)$ in the gas phase to $585 \mathrm{~cm}^{-1}\left(v_{2}\right)$ and $319 \mathrm{~cm}^{-1}\left(v_{3}\right)$ in an Ar-matrix, respectively. ${ }^{63,64,82}$ In solution, the $v_{2}$ and $v_{3}$ fundamental transitions shift from 585 and 325 $\mathrm{cm}^{-1}$ in cyclohexane to 545 and $310 \mathrm{~cm}^{-1}$ in acetonitrile. ${ }^{65,66}$ With respect to the structural isomer, $\mathrm{ClON}$ is predicted to have an even shorter NO bond length $(1.127 \AA$ ) than diatomic NO whereas the $\mathrm{ClO}$ bond length is predicted to be extremely long $(2.273 \AA) .{ }^{83}$ Calculations also suggest that the ionic contribution to the bonding in $\mathrm{CINO}$ and $\mathrm{ClON}$ may be a key factor in relative stability of the isomer. ${ }^{81,83}$ Given the ionic nature of $\mathrm{ClO}$ bond, the environment surrounding $\mathrm{ClON}$ is expected to significantly influence geometry and state energetics leading to solvatochromic behavior. A similar hypothesis has also been made for the structural isomer of dichlorine monoxide, $\mathrm{ClClO} .{ }^{35}$ Here the absorption band of $\mathrm{ClClO}$ in perfluorohexane was proposed to be $55 \mathrm{~nm}$ red shifted compared to the absorption band of $\mathrm{ClClO}$ in matrix isolation due to the environmental dependence on the $\mathrm{Cl}-\mathrm{Cl}$ bond strength.

A second consideration with respect to assignment of the photoproduct absorption in chloroform to $\mathrm{ClON}$ is the magnitude of the observed optical density change. Inspection of the transient absorption spectra for CINO dissolved in chloroform reveals that the reduction in optical density due to ground-state depletion of CINO is 4 times less than the increase in optical density associated with photoproduct formation. This comparison implies that the maximum molar absorptivity of the photoproduct is at least 4 times greater than the molar absorptivity of CINO at $256 \mathrm{~nm}$. This is consistent with the relative absorptivity of halooxide isomers. Specifically, the molar absorptivities of $\mathrm{ClOO}$ and $\mathrm{ClClO}$ are more than twice as large as their more stable forms, $\mathrm{OClO}$ and $\mathrm{ClOCl} .{ }^{32,84}$ Thus, the CINO-photoproduct band in chloroform could correspond to formation of the isomer, $\mathrm{ClON}$.

The results and analysis presented above can be used to develop a picture of the photochemical reaction dynamics of $\mathrm{CINO}$ in solution. The transient absorption spectrum of $\mathrm{ClNO}$ in acetonitrile was successfully reproduced by assuming $\mathrm{Cl}$ and NO production occurs with a quantum yield of 0.75 . A subset of the initially produced $\mathrm{Cl}$ and $\mathrm{NO}$ undergoes geminate recombination in this solvent, resulting in the re-formation of CINO. In chloroform the photochemistry appears to be more complex. A portion of the optical density evolution can also be assigned to $\mathrm{Cl}$ and NO production; however, the width of the dominant photoproduct absorption band is not consistent with formation of the $\mathrm{Cl}$ :solvent charge-transfer complex. Instead, we have proposed that another photochemical channel is responsible for the photoproduct absorption band centered at $330 \mathrm{~nm}$ in this solvent whereas formation of the $\mathrm{Cl}$ :solvent charge-transfer complex contributes to the low absorbing background. Clarification and confirmation of the photochemical reaction dynamics of $\mathrm{CINO}$ require spectroscopic techniques capable of unequivocal structural identification of the photoproducts, and time-resolved vibrational spectroscopy studies are currently underway.

Acknowledgment. The National Science Foundation is acknowledged for their support of this work (CHE-0350191). Acknowledgment is also made to the donors of the Petroleum Research Fund, administered by the American Chemical Society. C.C.C. gratefully acknowledges support from the Ford Foundation.

\section{References and Notes}

(1) Rowland, F. S. Annu. Rev. Phys. Chem. 1991, 42, 731.

(2) Renard, J. B.; Pirre, M.; Robert, C.; Huguenin, D. J. Geophys. Res.Atmos. 1998, 103, 25383. 
(3) Solomon, S.; Borrmann, S.; Garcia, R. R.; Portmann, R.; Thomason, L.; Poole, L. R.; Winker, D.; McCormick, M. P. J. Geophys. Res.-Atmos. 1997, 102, 21411

(4) Donsig, H. A.; Herridge, D.; Vickerman, J. C. J. Phys. Chem. A 1998, $103,9211$.

(5) Vaida, V.; Simon, J. D. Science 1995, 268, 1443.

(6) Reid, P. J. J. Phys. Chem. A 2002, 106, 1473.

(7) Cooksey, C. C.; Reid, P. J. Photochem. Photobiol. 2004, 80, 386

(8) Arkell, A.; Schwager, I. J. Am. Chem. Soc. 1967, 89, 5999.

(9) Rochkind, M. M.; Pimentel, G. C. J. Chem. Phys. 1967, 46, 4481

(10) Mueller, H. S. P.; Willner, H. J. Phys. Chem. 1993, 97, 10589.

(11) Thogersen, J.; Jepsen, P. U.; Thomsen, C. L.; Poulsen, J. A.; Byberg,

J. R.; Keiding, S. R. J. Phys. Chem. A 1997, 101, 3317.

(12) Philpott, M. J.; Charalambous, S.; Reid, P. J. Chem. Phys. Lett. 1997, 281,1 .

(13) Thogersen, J.; Thomsen, C. L.; Poulsen, J. A.; Keiding, S. R. J. Phys. Chem. A 1998, 102, 4186.

(14) Poulsen, J. A.; Thomsen, C. L.; Keiding, S. R.; Thogersen, J. J. Chem. Phys. 1998, 108, 8461. 207.

(15) Philpott, M. J.; Hayes, S. C.; Reid, P. J. Chem. Phys. 1998, 236,

(16) Hayes, S. C.; Philpott, M. J.; Reid, P. J. J. Chem. Phys. 1998, 109, 2596.

(17) Hayes, S. C.; Philpott, M. P.; Mayer, S. G.; Reid, P. J. J. Phys. Chem. A 1999, 103, 5534.

(18) Thomsen, C. L.; Philpott, M. P.; Hayes, S. C.; Reid, P. J. J. Chem. Phys. 2000, 112, 505 .

(19) Thomsen, C. L.; Reid, P. J.; Kieding, S. R. J. Am. Chem. Soc. 2000 , 122,12795 .

(20) Philpott, M. J.; Hayes, S. C.; Thomsen, C. L.; Reid, P. J. Chem. Phys. 2001, 263, 389

(21) Hayes, S. C.; Thomsen, C. L.; Reid, P. J. J. Chem. Phys. 2001, 115,11228 .

(22) Edgecombe, F. H. C.; Norrish, R. G. W.; Thrush, F. R. S.; Thrush,

B. A. Proc. R. Soc. London A 1957, 243, 24.

(23) Basco, N.; Dogra, S. K. Proc. R. Soc. London A 1971, 323, 401

(24) Sander, S. P.; Friedl, R. R. J. Phys. Chem. 1989, 93, 4764.

(25) Chichinin, A. I. Chem. Phys. Lett. 1993, 209, 459.

(26) Nelson, C. M.; Moore, T. A.; Okumura, M.; Minton, T. K. J. Chem. Phys. 1994, 100, 8055 .

(27) Nickolaisen, S. L.; Miller, C. E.; Sander, S. P.; Hand, M. R. Williams, I. H.; Francisco, J. S. J. Chem. Phys. 1996, 104, 2857.

(28) Moore, T. A.; Okumura, M.; Minton, T. K. J. Chem. Phys. 1997, 107,3337 .

(29) Tanaka, Y.; Kawasaki, M.; Matsumi, Y.; Fujiwara, H.; Ishiwata, T.; Rogers, L. J.; Dixon, R. N.; Ashfold, M. N. R. J. Chem. Phys. 1998 109, 1315.

(30) Smith, G. D.; Tablas, F. M. G.; Molina, L. T.; Molina, M. J. J. Phys. Chem. A 2001, 105, 8658.

(31) Chi, F. K.; Andrews, L. J. Phys. Chem. 1973, 77, 3062.

(32) Johnsson, K.; Engdahl, A.; Nelander, B. J. Phys. Chem. 1995, 99, 3965.

(33) Gane, M. P.; Williams, N. A.; Sodeau, J. R. J. Chem. Soc., Faraday T. 1997, 93, 2747.

(34) Esposito, A. P.; Reid, P. J.; Rousslang, K. W. J. Photochem. Photobiol. A Chem. 1999, 129, 9

(35) Cooksey, C. C.; Reid, P. J. J. Phys. Chem. A 2003, 107, 5508.

(36) Colburn, C. B. Developments in Inorganic Nitrogen Chemistry; Elsevier Scientific Publishing Co.: New York, 1973.

(37) Finlayson-Pitts, B. J.; Pitts, J. N., Chemistry in the Upper and Lower Atmosphere; Academic Press: New York, 2000.

(38) Luick, T.; Heckert, R.; Schulz, K.; Disselkamp, R. J. Atmos. Chem. 1999, 32, 315

(39) Engelman, R.; Rouse, P. E. J. Mol. Spectrosc. 1971, 37, 240.

(40) Werner, L.; Wunderer, B.; Walther, H. Chem. Phys. 1981, 60, 109.

(41) Moser, M. D.; Weitz, E.; Schatz, G. C. J. Chem. Phys. 1983, 78, 757.

(42) Bechara, J.; Morrow, T.; McGrath, W. D. Chem. Phys. Lett. 1985 , 122,605 .

(43) Bruno, A. E.; Bruhlmann, U.; Huber, J. R. Chem. Phys. 1988, 120, 155
(44) Ticktin, A.; Bruno, A. E.; Bruhlmann, U.; Huber, J. R. Chem. Phys.

1988, 125,403 .

(45) Bai, Y. Y.; Ogai, A.; Qian, C. X. W.; Iwata, L.; Segal, G. A.; Reisler, H. J. Chem. Phys. 1989, 90, 3903

(46) Bell, A. J.; Pardon, P. R.; Frey, J. G. Mol. Phys. 1989, 67, 465

(47) Bell, A. J.; Frey, J. G. Mol. Phys. 1990, 69, 943.

(48) Ogai, A.; Qian, C. X. W.; Reisler, H. J. Chem. Phys. 1990, 93, 1107.

(49) Cao, J. Y.; Wang, Y. F.; Qian, C. X. W. J. Chem. Phys. 1995, $103,9653$.

(50) Haas, B. M.; Felder, P.; Huber, J. R. Chem. Phys. Lett. 1991, 180, 293.

(51) Gillan, I. T. F.; Denvir, D. J.; Cormican, H. F. J.; Duncan, I.; Murrow, T. Chem. Phys. 1992, 167, 193.

(52) Kim, H. L.; Mo, Y.; Matsumi, Y.; Kawasaki, M. Bull. Korean Chem. Soc. 1992, 13, 162.

(53) Felder, P.; Morley, G. P. Chem. Phys. 1994, 185, 145.

(54) Kawasaki, M.; Suto, K.; Sato, Y.; Matsumi, Y.; Bersohn, R. J. Phys. Chem. 1996, 100, 19853

(55) Skorokhodov, V.; Sato, Y.; Suto, K.; Matsumi, Y.; Kawasaki, M. J. Phys. Chem. 1996, 100, 12321.

(56) Mackey, J. L.; Johnson, B. R.; Kittrell, C.; Le, L. D.; Kinsey, J. L.

J. Chem. Phys. 2001, 114, 6631.

(57) Goodeve, C. F.; Katz, S. Proc. R. Soc. A 1939, 172, 432 941.

(58) Ballash, N. M.; Armstrong, D. A. Spectrochim. Acta 1974, 30A

(59) Solgadi, D.; Lahmani, F.; Lardeux, C. Chem. Phys. 1983, 79, 1983. (60) Lacombe, S.; Loudet, M.; Dargelos, A.; Camou, J. M. Chem. Phys. 2000, 258, 1 .

(61) Yamashita, T.; Kato, S. J. Chem. Phys. 2003, 119, 4251.

(62) Ning, C.; Pfab, J. Chem. Phys. Lett. 1993, $216,87$.

(63) Hallou, A.; Schriver-Mazzuoli, L.; Schriver, A.; Chaquin, P. Chem Phys. 1998, 237, 251

(64) Maier, G.; Reisenauer, H. P.; De Marco, M. Chem. Eur. J. 2000 6,800 .

(65) Barham, B. P.; Reid, P. J. Chem. Phys. Lett. 2002, 361, 49

(66) Nyholm, B. P.; Reid, P. J. J. Phys. Chem. B 2004, 108, 8716.

(67) Elles, C. G.; Cox, M. J.; Barnes, G. L.; Crim, F. F. J. Phys. Chem

A 2004, 108, 10973.

(68) Pass, G.; Sutcliffe, H., Practical Inorganic Chemistry: Preparation, Reactions and Instrumental Methods; Chapman and Hall: London, 1968.

(69) Jenner, E. L. J. Org. Chem. 1962, 27, 1031.

(70) Knovel Solvents - A Properties Database; Wypych, G., Ed.; ChemTec Publishing: Toronto, 2000.

(71) Okabe, J. Photochemistry of Small Molecules; Wiley-Interscience: New York, 1978

(72) Chateauneuf, J. E. Chem. Phys. Lett. 1989, 164, 577.

(73) Schindler, R. N.; Liesner, M.; Schmidt, S.; Kirchner, U.; Benter,

T. J. Photochem. Photobiol. A 1997, 107, 9.

(74) Krisch, M. J.; McCunn, L. R.; Takematsu, K.; Butler, L. J.; Blase,

F. R.; Shu, J. J. Phys. Chem. A 2004, 108, 1650.

(75) Klaning, U. K.; Wolff, T. Ber. Bunsen-Ges. Phys. Chem. 1985, 89,243

(76) Treinin, A.; Hayon, E. J. Am. Chem. Soc. 1975, 97, 1716.

(77) Buhler, R. E. J. Phys. Chem. 1972, 76, 3220.

(78) Thomsen, C. L.; Madsen, D.; Poulsen, J. A.; Thogersen, J.; Knak

Jensen, S. J.; Keiding, S. R. J. Chem. Phys. 2001, 115, 9361.

(79) Cazzoli, G.; Esposti, C. D.; Palmieri, P.; Simeone, S. J. Mol. Spectrosc. 1983, 97, 165 .

(80) Pauling, L. The Nature of the Chemical Bond; Cornell University: New York, 1960

(81) Meredith, C.; Quelch, G. E.; Schaeffer, H. F. J. Chem. Phys. 1992 96,480

(82) McDonald, J. K.; Merritt, J. A.; Kalasinsky, V. F.; Heusel, H. L.; Durig, J. R. J. Mol. Spectrosc. 1986, 117, 69.

(83) Lee, T. J. Chem. Phys. Lett. 1994, 223, 431

(84) Demore, W. B.; Sander, S. P.; Golden, D. M.; Hampson, R. F.; Kurylo, M. J.; Howard, C. J.; Ravishankara, A. R.; Kolb, C. E.; Molina, M. J., Chemical Kinetics and Photochemical Data for Use in Stratospheric Modeling; Jet Propulsion Laboratory: Pasadena, CA, 1994. 